\title{
Vertentes propositivas para a mediação da informação
}

\section{Propositional trend for information mediation}

\section{Tendencias proposicionales para la mediación de la información}

Correspondência

Autor para correspondência: Marcos Aparecido Rodrigues do Prado

Endereço completo: Primeira Travessa São Pedro, no 20, Praia de Garça Torta, Maceió Alagoas. CEP: 57039-022

E-mail: marcos.prado@ichca.ufal.br ORCID: https://orcid.org/0000-0001-8783$\underline{3280}$

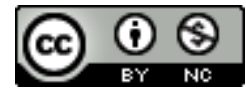

Submetido em: 07/01/2020

Aceito em: 24/05/2020

Publicado em: 10/06/2020

${ }_{1}^{1}$ Professor Adjunto do Curso de Biblioteconomia, ICHCA/UFAL. Graduado em Biblioteconomia pela UEL, mestre e doutor em Ciência da Informação pela Unesp Marília. E-mail: marcos.prado@ichca.ufal.br ${ }^{2}$ Estudante de graduação do Curso de Biblioteconomia, ICHCA/UFAL. E-mail: dimitria.v.s@gmail.com 


\title{
RESUMO
}

A mediação da informação se caracteriza por um processo articulado da interferência realizada pelos profissionais da informação com os usuários de recursos e ambientes informacionais. Por conseguinte, os bibliotecários assumem um papel significativo para estruturar as atividades de mediação visando estabelecer prioridades na interlocução do usuário em que a noção de subjetividade individual se apresenta como característica da essência humana. Logo, a mediação da informação envolve um conjunto de ações, inclusive políticas, para determinar a amplitude da representação social do indivíduo. Assim, o presente artigo tem como propósito fundamental ampliar as reflexões teóricas da mediação da informação pelo protagonismo social, acolhimento e empoderamento. Tais condições são entendidas como vertentes propositivas operacionalizadas como dinâmicas interativas que notabilizam o foco no desenvolvimento das capacidades de consciência social do usuário. Na abordagem deste estudo a mediação da informação se desenvolve por meio de atitudes representativas para provocar mudanças que permitem ao indivíduo se empoderar por tomar consciência de seu espaço histórico e cultural na sociedade. Neste sentido, utiliza-se de fundamentos teóricos extraídos da saúde pública estabelecendo diálogos propositivos com a Ciência da Informação. Portanto, tendo como base os ideais da universalização da saúde, os usuários de bibliotecas e sistemas de informação são assumidamente tratados como sujeitos prioritários frente aos desafios de mediação da informação pelas formas implícitas ou explícitas desse processo.

Palavras-chave: Acolhimento. Empoderamento. Mediação da informação. Protagonismo social. Usuário.

\begin{abstract}
Information mediation is characterized by an articulated interference process involving information professionals and users of information resources and environments. Therefore, librarians play a significant role in structuring mediation activities in order to establish priorities in the user's dialogue, in which the notion of individual subjectivity presents itself as a characteristic of the human essence. Thus, information mediation involves a set of actions, including policies, to determine the breadth of the individual's social representation. In this context, this article has, as its fundamental purpose, to broaden the theoretical reflections on information mediation through social protagonism, user embracement and empowerment. Such conditions are understood as propositional trends operationalized as interactive dynamics that highlight the focus on the development of the user's social awareness capacities. In this study's approach, information mediation is developed through representative attitudes to bring about changes that enable the individuals to empower themselves by becoming aware of their historical and cultural space in society. Therefore, users of libraries and information systems are admittedly treated as priority subjects of the librarian's work in the face of the challenges posed by information mediation through implicit or explicit forms of this process.
\end{abstract}

Keywords: Empowerment. Information mediation. Social protagonism. User. User embracement.

\section{RESUMEN}

La mediación de la información se caracteriza por un proceso articulado de interferencia de profesionales de la información con los usuarios de recursos y entornos de información. Por lo tanto, los bibliotecarios tienen un papel importante en la estructuración de las actividades de mediación para establecer prioridades en el diálogo del usuario, en el que la noción de subjetividad individual se presenta como una característica de la esencia humana. Así, la mediación de información implica un conjunto de acciones, las políticas incluidas, para determinar la amplitud de la representación social del individuo. En este contexto, este artículo tiene como objetivo fundamental ampliar las reflexiones teóricas de la mediación de la información a través del protagonismo social, la recepción del usuario y el empoderamiento. Tales condiciones se entienden como direcciones proposicionales operacionalizados como dinámicas interactivas que resaltan el enfoque en el desarrollo de las capacidades de conciencia social del usuario. En el enfoque de este estudio, la mediación de la información se desarrolla a través de actitudes representativas para lograr 
cambios que permitan a lo individuo empoderarse al tomar conciencia de su espacio histórico y cultural en la sociedad. Por lo tanto, los usuarios de bibliotecas y sistemas de información son tratados como un tema prioritario del trabajo del bibliotecario frente a los desafíos que plantea la mediación de la información a través de formas implícitas o explícitas de este proceso.

Palabras clave: Empoderamiento. Mediación de información. Protagonismo social. Recepción del usuario. Usuario.

\section{INTRODUÇÃO}

O presente estudo reflete a mediação da informação considerando a combinação de atitudes como vertentes a serem exploradas por este processo. Assim, o protagonismo social, o acolhimento e o empoderamento correspondem a princípios fundamentais da interação entre o profissional da informação com o usuário. Partindo do estabelecimento dessa ideia como elemento teórico propositivo destaca-se a importância do papel do bibliotecário na mediação da informação.

Embasado pelo compromisso social ao qual se espera que bibliotecário ofereça como diferencial da sua competência profissional para atuar na sociedade, tais vertentes assumem uma relevância ímpar e significativa. Dito isso, o objetivo deste artigo consiste em apresentar contribuições teóricas que refletem novas perspectivas à mediação da informação e resultando na atuação consciente da interferência estabelecida pelo bibliotecário.

Metodologicamente este estudo se fundamenta por uma revisão de literatura nutrida por diálogos multidisciplinares com destaque ao subsídio conceitual de publicações científicas do domínio de saúde pública. Esta especialidade de área do conhecimento foi selecionada por oferecer inúmeros trabalhos que definem e caracterizam atitudes humanizadoras que prezam 
pelo respeito às diferenças e o bem-estar dos usuários do sistema de saúde pública. Portanto, Biblioteconomia e Ciência da Informação são fundamentalmente refletidas nas perspectivas da mediação da informação pelo aporte teórico de elementos conceituais extraídos da saúde pública. No entanto, faz-se mister apresentar esclarecimentos de que a mediação da informação representa um processo ao qual o bibliotecário protagoniza visando ampliar as capacidades de desenvolvimento intelectual e da consciência humana aos usuários.

Notadamente, o presente artigo almeja potencializar as discussões e reflexões teóricas em que a mediação da informação assume relevância primordial à condição de objeto da Ciência da Informação.

\section{ASPECTOS FUNDAMENTAIS DO PROTAGONISMO SOCIAL}

Conceitualmente adota-se a definição de protagonismo social que Gomes (2019) atribui à consciência de pertencimento dos indivíduos inseridos em um determinado contexto histórico e sociocultural. Nesse sentido, "[...] representa, em sua essência, uma ação de resistência contra a opressão, discriminação, apartheid social, rejeição, desrespeito e negação ao diferente [...]" (GOMES, 2019, p. 11).

É importante ressaltar que a expressão "protagonismo social" compreende a uma dinâmica multifacetada da qual abre margem de interesse interdisciplinar. Essas abordagens diversificadas oferecem inúmeras contribuições para a formação do seu significado conceitual. No entanto, precede o sentido de representar a "[...] luta por direitos de diferentes naturezas" 
(PERROTTI, 2017, p. 13). Logo, o protagonismo se expressa como uma postura de luta e empoderamento pela consciência de sua identidade social.

Desse modo, entende-se que o protagonista social tem como objetivo provocar mudanças e atitudes no ambiente do qual ele faz parte. Assim sendo, reconhece-se que o protagonista é um ator social que representa papel estrategicamente importante em um determinado contexto. Logo, trata-se de um indivíduo que procura estimular ideias e que reconhece no seu próximo a capacidade de intervir no meio social, ocasionando transformações direcionadas às realidades do cotidiano (FARIAS; COSTA, 2017; GOMES; NOVO, 2017). Enfim, o protagonista é o agente consciente do seu papel e da sua função social e imbuído dessas responsabilidades age proativamente pelas suas competências adequando recursos que gerem autonomia crítica aos envolvidos.

De acordo com Gomes (2017, p. 27):

O protagonismo social representa o caminho humanizador do mundo e, portanto, promissor da construção ética de relações sociais capazes de assegurar o espaço crítico, de dialogia, criatividade e alteridade.

Em tal perspectiva, o protagonista intervém socialmente como um mediador consciente do seu papel e da sua função na adversa realidade de atuação à qual compreende o seu envolvimento profissional.

Vale destacar que o protagonista social luta não somente por igualdade e oportunidades. Em sua essência, esse agente social também atua para que outros indivíduos se tornem sujeitos conscientes e empoderados possibilitando articular 
transformações sociais no meio ao qual pertencem e que ao mesmo tempo desenvolvam o sentimento de pertencimento na sociedade.

Para Perrotti (2017, p. 14), o protagonismo social:

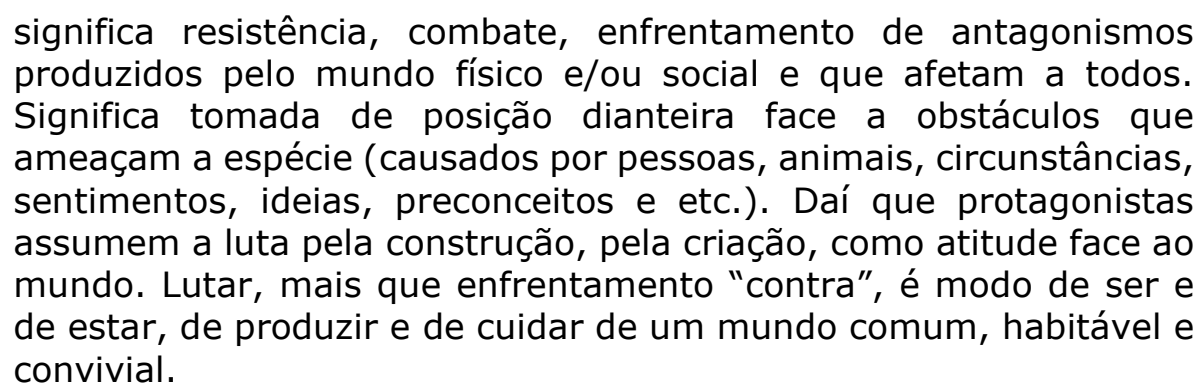

Ainda, segundo Perrotti (2017), o protagonismo indica um lugar, que na perspectiva específica do autor supracitado remete a algo visível e exposto, ou seja, é uma luta que não se dá em ambientes ocultos, íntimos ou privados. Pelo contrário, é lugar de evidente visibilidade e com perspectivas inclusivas. Em tal condição, idealiza o pertencimento a todos os indivíduos, isto é, assumindo os espaços e as esferas públicas como lugar de convivência sem distinção.

O bibliotecário pode, e deve, atuar como protagonista social em qualquer esfera da Biblioteconomia e da Ciência da Informação. Desse modo, o bibliotecário como protagonista idealiza na mediação da informação as condições significativas a fim de se potencializar a interatividade com o usuário para ampliar experiências recíprocas aos recursos informacionais. Esse profissional opera a mediação de forma implícita e/ou explícita para satisfazer as necessidades informacionais de seus usuários, que se encontram inseridos em recortes sociais. Mas é importante enfatizar que a satisfação informacional nunca é plena e absoluta. Pois, segundo Almeida Júnior (2015a), o acesso 
à informação comumente provoca incertezas e dúvidas no sujeito e, com isso, novas necessidades que exigem reformulações de estratégias da mediação da informação.

Sendo assim, o papel desse profissional não se resume às ações sociais e culturais, tão pouco, ao serviço de referência e informação. Araújo (2017, p. 130) e Farias (201) reconhecem a importância do protagonismo social como uma forma de intervenção bibliotecária com propósitos específicos visando a apropriação da informação. Nesse sentido, ambos os autores supracitados consideram que a prática profissional é regida por experiências fundamentais que direcionam o tratamento da informação.

No entanto, Vergueiro (1994, p. 9) enfatiza que os bibliotecários "[...] não devem permitir que as suas crenças e opiniões a respeito do conteúdo dos documentos possam interferir em seu trabalho de seleção de materiais para o acervo". Apesar desta necessária ausência de intenções deterministas, o trabalho bibliotecário não possui neutralidade, imparcialidade ou isenção, conforme criticamente discute Almeida Júnior (2015a; 2015b). Tais perspectivas remetem à ideia defendida por Freire (1981) de que os posicionamentos representam manifestações de preferências, inclusive ideológicas. Ainda segundo Freire (1981), é importante identificar e reconhecer o quanto a orientação de seus valores pessoais ou individuais remete a princípios que condicionam a lógica de inclusão ou exclusão. Para Farias e Costa (2017, p. 4) "[...] isso significa dizer que esse 
profissional deve se preocupar e estar atento às demandas dos usuários, para o uso da informação de maneira mais consciente". Contudo, apesar das boas intenções envolverem justificativas comumente apresentadas pelos bibliotecários na mediação da informação, ressalta-se que os níveis de interferências não excluem os propósitos de manipulações no processo. Afinal, como reconhecem Almeida Júnior e Bortolin (2008, p. 74), "A linha que separa a interferência da manipulação é extremamente tênue".

Frente aos desafios de uma postura profissional articulada e comprometida com as necessidades específicas de informação em uma comunidade diversificada de sujeitos sociais é que o protagonismo se faz necessário às rotinas bibliotecárias. Em tal direção se reconhece a pertinência e a relevância do tema aqui tratado, especialmente em momento histórico de polarização política sobre a situação atual na sociedade brasileira. Logo, torna-se enfática a ideia de Farias (2017) que enxerga no perfil do protagonista social como alguém intencionado a contribuir com o seu meio de atuação profissional. Desse modo, o protagonista social

[...] pode também ser estimulado pelo desenvolvimento de competências em informação, as quais tendem a possibilitar ao bibliotecário: antever problemas, responder prontamente aos questionamentos de forma solícita, se dispondo a aprender continuamente; utilizar os recursos disponíveis para obter sucesso nas atividades empreendidas, formulando estratégias, e mostrandose hábil para superar obstáculos diários durante a execução de suas atividades (FARIAS, 2016, p. 107).

Perrotti (2017, p. 16) identifica que dentre as qualidades de um sujeito protagonista consta a postura desse em tomar para si uma forma de ser, reconhecendo no outro como semelhante e 
dotado de uma identidade própria diante de uma sociedade múltipla. Ou seja, protagonista social valoriza a empatia com a diversidade social atuando profissionalmente a permitir estruturas de representações compatíveis com as necessidades informacionais específicas. Para Moura (2017, p. 96) "O protagonismo revela a centralidade e a pertinência da participação social de sujeitos identificados como ação coletiva necessária a transformação social e a construção histórica". Assim, a atuação profissional comprometida pela atitude de protagonismo social é, além de tudo, uma busca constante pela troca de conhecimentos e saberes de diferentes níveis e significados, o que faz da interação um elemento determinante nos processos sociais (PERROTTI, 2017).

No entanto, se faz necessário enfatizar o comprometimento efetivo do profissional envolvido no processo de mediação da informação. Refletindo essa questão Farias e Varela (2017, p. 93) esclarecem que o mediador da informação deve se desprender,

[...] de ideias conversadoras e estáticas, para poder sentir as demandas de um grupo, se conscientizando de seu papel na sociedade perante a responsabilidade social da área em que atua, procurando incentivar a tolerância e abertura por parte dessa sociedade face à diversidade cultural e étnica dos que vivem à margem.

Logo, a mediação da informação está diretamente relacionada com a capacidade de o profissional empreender estruturas acolhedoras que são representadas nas minúcias da sua atuação e no seu protagonismo social. Pois é por meio do protagonismo social que se consegue construir espaços físicos de acolhimentos e representatividades para as comunidades 
marginalizadas, sendo estes entendidos como locais seguros para as suas demonstrações sociais e culturais. Com isso, entende-se que "Consciência e respeito ao diferente (ao outro) e ao seu espaço de voz no processo de interação são elementos importantes e decisivos para a vida ativa" (GOMES, 2017, p. 38). Envolvido pelo comprometimento profissional, caracterizado com o protagonismo social, é possível construir ambientes mais humanizados com pessoas aptas e que identificam o real valor do usuário de equipamentos informacionais, compreendendo especialmente as bibliotecas. Nessa perspectiva, segundo Gomes (2017), o indivíduo que trabalha com informação também é considerado como um "sujeito de ação protagonista". Pois suas atitudes e decisões são condicionadas diretamente pela mediação estabelecida a fim de se viabilizar o acesso e a apropriação da informação. Mas esse processo não é uma aquisição automática para geração de conhecimentos, afinal, envolve complexidades individuais de certezas e incertezas. Farias (2017, p. 183) considera que "O tratamento e a difusão da informação interferem na formação e transformação de consciências". Portanto, é pela informação, entendida como fator determinante para alterar estruturas pessoais e individuais, que a mediação encontra no protagonismo social a sua dimensão mais comprometida para atuação profissional do bibliotecário.

Para isso, é importante a compreensão da informação como um recurso socialmente construído e que estabelece relações de afinidades com as diversas esferas correspondentes aos fatores 
de comunicação. Nesse ponto de vista o entendimento informacional se dá pelos processos comunicacionais que são elaborados por meios e canais apropriados da condição humana. São circunstâncias que interferem na realidade de uma biblioteca enquanto unidade de informação e ambiente viável à socialização. Consequentemente, o protagonismo social se faz necessário nessa realidade para mediar e reafirmar identidades e, com isso, favorecer alternativas suscetíveis ao empoderamento.

Ressalta-se que a ênfase do trabalho do bibliotecário consiste na apropriação da informação. Assim, para que este profissional cumpra o seu papel social também deve assumir a sua condição de protagonista, cuja responsabilidade social consiste em organizar, preservar, disseminar, recuperar a informação para o acesso, uso e apropriação pela comunidade usuária. Tais condições favorecem o compromisso de fomentar o espaço da interlocução entre os sujeitos em uma dinâmica frenética que modifica constantemente 0 seu repertório informacional (GOMES, 2017). Logo, entende-se que é pelas reservas de informações que o ser humano, enquanto sujeito histórico e sociocultural, articula a sua cognição para interpretar e contextualizar o meio em que vive e, com isso, gerar e aperfeiçoar conhecimentos.

Diante do exposto, se reconhece que é pela mediação da informação a que o protagonismo social encontra o seu ápice de responsabilidade na atuação profissional do bibliotecário frente aos desafios e adversidades da sua profissão. Nessa perspectiva, 
entende-se que "[...] a mediação não estaria restrita apenas às atividades relacionadas diretamente ao público atendido, mas em todas as ações do profissional bibliotecário, em todo o fazer desse profissional" (ALMEIDA JÚNIOR, 2008, p. 46). Disto isso, considera-se oportuna e essencial a apresentação da definição conceitual defendida por este artigo a respeito de mediação da informação. Assim sendo, orienta-se 0 entendimento considerando que a mediação da informação se refere a:

Toda ação de interferência - realizada em um processo, por um
profissional da informação e na ambiência de equipamentos
informacionais -, direta ou indireta; consciente ou inconsciente;
singular ou plural; individual ou coletiva; visando a apropriação de
informação que satisfaça, parcialmente e de maneira momentânea,
uma necessidade informacional, gerando conflitos e novas
necessidades informacionais (ALMEIDA JúNIOR, 2015a, p. 25).

Notadamente, se percebe a importância do domínio da ação bibliotecária pela mediação da informação a fim de contribuir com o usuário visando aprimorar as estruturas da sua representação na identidade social. Desse modo, entende-se que é pelo protagonismo social a interface proativa do bibliotecário para efetivamente se comprometer com o desenvolvimento do usuário. Frente às reflexões apresentadas destaca-se que tais ideais representam fundamentos almejados para uma biblioteca realmente consciente e engajada com as questões sociais. Assim, esta instituição deveria assumir os desafios de acolher a sua comunidade usuária reconhecendo as individualidades como características subjetivas dos sujeitos envolvidos em uma diversidade social. 
Frisando o contexto acima apresentado, Figueiredo (1992, p. 68, grifo da autora) identifica que o bibliotecário precisa, necessariamente:

[...] ter empatia para com o usuário, não manter nenhum tipo de preconceito em relação à pessoa ou à questão, e não permitir que o seu ponto de vista pessoal interfira no trabalho que tem que realizar como profissional.

Portanto, o bibliotecário que assume o seu papel de protagonista social em uma determinada instituição recebe o desafio de integrar e adaptar os conhecimentos técnicos acerca da profissão. Isso somente é possível quando este profissional interage com o olhar social-comunitário e for sensível em proporcionar mudanças estruturais cotidianas, tornando assim a biblioteca como um ambiente inclusivo e pertencente a todas e todos.

\section{VERTENTES PROPOSITIVAS PARA A MEdIAÇÃo DA INFORMAÇÃO}

Considerando a importância aqui retratada no processo de mediação da informação este artigo implementa propostas de representação ilustrativa em que três vertentes assumem a ênfase resultante da interferência do bibliotecário na sua relação informacional com o usuário. Assim, destaca-se que a Figura 1 contextualiza a noção da mediação da informação como dinâmica interativa iniciada pelo protagonismo social devidamente caracterizada enquanto vertente principiante do processo em questão. Visualmente consta na sequência da Figura 1 a demarcação propositiva das vertentes de acolhimento e 
empoderamento como princípios da sucessão encadeada pela mediação da informação.

Figura 1 - Diagrama das vertentes de mediação da informação

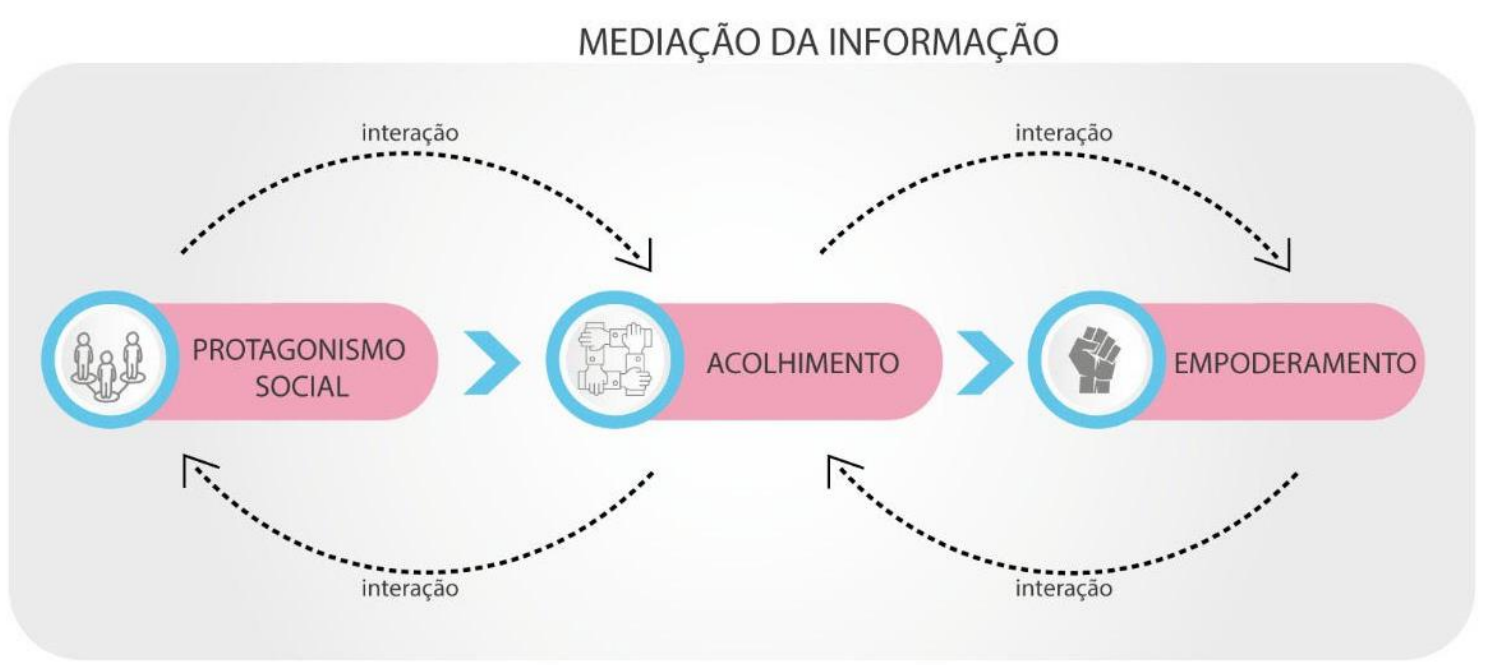

Fonte: elaborada pelos autores (2019).

A Figura 1 contempla três enfoques estabelecidos pela mediação da informação considerados como vertentes fundamentais para o desenvolvimento desse processo. De pronto, observa-se que o protagonismo social se encontra como uma etapa crucial para a concretização das ações mediadoras que visam o necessário atendimento do usuário, considerando as suas subjetividades. Vale ressaltar que o protagonismo social inserido na mediação da informação reforça o empenho do profissional bibliotecário para os compromissos de respeito às individualidades e os princípios éticos de responsabilidade social. Outro aspecto que merece ser esclarecido condiz ao sentido de "atendimento do usuário" aqui defendido englobando todas as práticas profissionais envolvidas pelo fazer bibliotecário. Assim, a expressão não se restringe a uma atividade interativa em que se recorre unicamente pelo emprego da assistência oferecida na mediação explícita. Logo, evidencia-se a relevância assumida 
nas questões implícitas que repercutem na mediação da informação como fatores de representação tácita, consciente ou inconscientemente.

Em seguida, a Figura 1, estabelece a ocorrência da segunda etapa em que se refere à idealização do acolhimento dos usuários, valendo-se de recursos e serviços informacionais oferecidos pela biblioteca. Esta fase se refere ao tratamento dispensado pelo bibliotecário para viabilizar representatividade ao usuário pelas formas de mediação, implícita e explícita. Destaca-se que o protagonismo social exerce papel fundamental no processo por este demonstrar empatia acolhedora pelas manifestações diversas que caracterizam as subjetividades dos usuários.

Por fim, a terceira etapa do diagrama representado na Figura 1. Em tal situação consagra-se o empoderamento como resultado do protagonismo social visando acolher os usuários pela mediação da informação. Assim, entende-se que a função do protagonismo social somente se legitima quando o seu resultado é promover o acolhimento para empoderar os usuários, considerando as identidades desses sujeitos em âmbitos sociais e culturalmente. Dito isso, notabiliza-se que a mediação da informação configura a um processo de relevante importância na atuação profissional do bibliotecário. Afinal, em tal perspectiva, o empoderamento consiste na elevação da consciência do sujeito sobre a sua identidade e o seu lugar de fala e de vivência social, ou seja, seu autorreconhecimento como valor agregado da informação. 


\subsection{Acolhimento como princípio na Mediação da Informação}

A ideia fundamental que sustenta a concepção de acolhimento aqui defendida se refere ao conjunto de ações, conscientes ou inconscientes, que se manifesta tanto pela mediação implícita quanto explícita. Nesse sentido, acolher envolve a dimensão ética que Vergueiro (1994) identifica nas relações profissionais e institucionais para garantir o atendimento das necessidades informacionais do usuário. Logo, considera-se importe a adoção de critérios e políticas para orientar o atendimento como princípio norteador dos processos de mediação da informação.

Entende-se como necessária a ênfase de que o acolhimento não constitui exclusividade da assistência prestada ao usuário pelo Serviço de Referência e Informação, ou seja, incumbência restrita à mediação explícita em detrimento das suas formas implícitas. Assim, a seleção de materiais para compor os acervos bem como as atividades de organização e representação da informação são formas determinantes de se estabelecer mecanismos de acolhimento. Portanto, o acolhimento deve privilegiar todas as etapas do trabalho bibliotecário e ser sistematizado por políticas específicas que enfatizem a amplitude fundamental na orientação deste princípio.

Tomando como base a relevância do protagonismo social como atitude do bibliotecário frente ao processo de mediação da informação o acolhimento assume uma postura de profissionalismo e respeito com a comunidade usuária. Segundo 
Silva e Romano (2015, p. 364) o acolhimento representa o "[...] encontro mediado pela escuta e pelo vínculo, o que aciona um sentido de disponibilidade de tempo e compromisso para a sua realização". Nessa perspectiva, evidencia-se a prioridade do usuário considerando as subjetividades do indivíduo como valor institucional com ênfase no respeito à humanidade e as suas diversas formas de expressões e manifestações.

Dadas as características apresentadas 0 acolhimento assume como um fator indispensável a ser contemplado nos princípios de mediação da informação, especialmente para reforçar o caráter social da biblioteca.

\subsection{Empoderamento como Resultado de um Processo}

Como empoderamento se entende a capacidade reconhecida para determinar uma posição social que afirma o fortalecimento da sua identidade. De acordo com Kleba e Wendausen (2009, p. 735), é:

Através desse processo, [que] pessoas renunciam ao estado de tutela, de dependência, de impotência, e transformam-se em sujeitos ativos, que lutam para si, com e para os outros por mais autonomia e autodeterminação [...].

Assim, a consciência do indivíduo representa uma capacidade motriz para potencializar engajamentos visando transformar o meio social do qual pertence.

Na dinâmica do processo de mediação da informação o empoderamento configura uma etapa resultante das ações caracterizadas pelo protagonismo social em que o bibliotecário desenvolve as formas de acolhimento ao usuário. Desse modo, é pela mediação da informação que o empoderamento 
oportuniza ao sujeito as condições para ampliar o seu papel social. Assim, todo esse processo sensibiliza no indivíduo uma articulação mobilizada,

[...] dentro da sua realidade social, adquirindo novas formas de enxergar as perspectivas de uma construção de realidade, [com isso] o empoderamento se torna uma multiplicação de ideias transformadoras" (FARIAS; COSTA, 2017, p. 2).

No entanto, ressalta-se que tal perspectiva somente se concretiza quando há uma mediação transformadora em que o bibliotecário está devidamente comprometido com o protagonismo social. Logo, o acolhimento deve ser instituído como princípio fundamental da mediação da informação.

\section{CONSIDERAÇÕES FINAIS}

Estabelecidas as reflexões apresentadas, destaca-se que este artigo reforça a ideia da mediação da informação como um processo estratégico para o desenvolvimento social da função bibliotecária. Pois esta dinâmica interativa representa uma oportunidade do ambiente informacional para ampliar as suas competências e influenciar posturas mais engajadas na Biblioteconomia e na Ciência da Informação. Todavia, percebese a ênfase de se refletir o papel social do bibliotecário na relação com o usuário perpassando desde o tratamento documentário até os meios e as formas para disponibilidade no acesso da informação. Assim, entende-se que a mediação da informação representa um processo ao qual merece o estabelecimento de políticas institucionais embasadas em princípios que privilegiem o desenvolvimento da autonomia e autodeterminação do usuário. 
Frente aos desafios da mediação da informação em uma sociedade cada vez mais globalizada economicamente e amparada por tecnologias reafirma-se a importância das questões éticas levantadas por Vergueiro (1994). Assim, o protagonismo social que Gomes (2017; 2019) defende ao engajamento do exercício profissional do bibliotecário representa um caminho humanizador pela mediação da informação. Araújo (2017) reconhece que o protagonismo social do bibliotecário surge como uma categoria analítica focada na dimensão do sujeito e com grande potencial a se firmar como um campo teórico a opor-se ao determinismo profissional. Com isso, Almeida Júnior e Bortolin (2008) recomendam ser preciso superar os estigmas que persistem historicamente na função bibliotecária pela ênfase no controle da preservação documental em detrimento do acesso informacional pelo usuário.

Seguindo tais perspectivas, este artigo almeja uma ruptura no continuísmo em que "[...] os bibliotecários se atêm a aplicação de políticas já testadas e utilizadas em outros equipamentos informacionais, com pouca ou nenhuma adequação" (ALMEIDA JúNIOR, 2015b, p. 134). Afinal, as mudanças de paradigmas implicam no enfretamento de embates permanentes que insistem desacreditar a competência do novo e as reais possibilidades de transformações individuais e coletivas. Mas o conservadorismo que insiste na permanência estática é uma condição humana alimentada pelo medo da alteração de modelos estruturais e mentais. Infelizmente, "A Biblioteconomia e a Ciência da informação flertam, ambas, com 
o conservadorismo. Mais do que flertam, namoram e se casam com o conservadorismo" (ALMEIDA JúNIOR, 2015b, p. 133). No entanto, as mudanças no fazer bibliotecário são oportunidades para se testar e se vislumbrar novas perspectivas de soluções aos problemas informacionais. Com a mediação da informação não é diferente, desde que o usuário seja assumidamente centralizado como prioridade dos processos informacionais envolvidos.

Por fim, as vertentes aqui tratadas enfatizam a importância do compromisso profissional do bibliotecário frente aos desafios para envolver o usuário ao ponto desse se transformar por meio dos recursos informacionais oferecidos. Notadamente, o bibliotecário aqui retratado na sua responsabilidade profissional assume a competência de mediador da informação. Nesta função,

[...] terá a possibilidade de interferir eticamente no cotidiano do cidadão, fomentando o seu 'anseio' e a sua necessidade de ler e de buscar informação, para que ao construir conhecimento ele, consequentemente construa a sua vida (ALMEIDA JÚNIOR; BORTOLIN, 2008, p. 68).

Reconhecidamente a mediação da informação é um processo que está em pleno desenvolvimento de bases teóricas. Portanto, ainda carece de aportes sistematizados que incite repercussões efetivas e significativas no cotidiano profissional do bibliotecário. Desse modo, espera-se que o presente artigo provoque novas reflexões para amplificar as perspectivas de outros estudos a fim de se realçar o papel social do bibliotecário visando um protagonismo acolhedor ao usuário, logo, empoderando-o pela mediação da informação. 


\section{REFERÊNCIAS}

ALMEIDA JÚNIOR, O. F. Mediação da informação: ampliando o conceito de disseminação. In: VALENTIM, M. L. P. (Org.). Gestão da informação e do conhecimento no âmbito da Ciência da Informação. São Paulo: Polis: Cultura Acadêmica, 2008. Cap. 3, p. 41-54.

ALMEIDA JÚNIOR, O. F. Mediação da informação: um conceito atualizado. In: BORTOLIN, S.; SANTOS NETO, J. A.; SILVA, R. J. Mediação oral da informação e da leitura. Londrina: ABECIN, 2015a. Cap. 1, p. 9-32.

ALMEIDA JÚNIOR, O. F. Conservadorismo e revolução (ou reformismo) na Biblioteconomia e na Ciência da Informação. Divers@: Revista Eletrônica Interdisciplinar, Matinhos, v. 8, n. 2, p. 132-144, jul./dez. 2015b.

ALMEIDA JÚNIOR, O. F.; BORTOLIN, S. Mediação da informação e da leitura. In: SILVA, T. E. (Org). Interdisciplinaridade e transversalidade em Ciência da Informação. Recife: NÉCTAR, 2008. p. 67-85.

ARAÚJO, C. A. A. Protagonismo como categoria analítica em estudos de usuários da informação. In: GOMES, Henriette Ferreira; NOVO, Hildenise Ferreira (Org.). Informação e protagonismo social. Salvador: Edufba, 2017. p. 129-146.

FARIAS, M. G. G. Mediação e competência em informação: proposições para a construção de um perfil de bibliotecário protagonista. Revista Ciência da Informação e Documentação, Ribeirão Preto, v. 6, n. 2, p.106-125, fev. 2016.

FARIAS, M. G. G.; COSTA, D. A. Empoderamento e protagonismo social no setor de referência de bibliotecas universitárias. Encontros Bibli: revista eletrônica de Biblioteconomia e Ciência da Informação, Florianópolis, v. 22 , n. 50, p. 1-14, set. 2017.

FARIAS, M. G. G.; VARELA, A. V. A mediação da informação e o protagonismo social: experimentando a construção de um modelo em uma comunidade brasileira. Investigación Bibliotecológica, México (DF), v. 31, n. 73, p. 91-110, sept./dic., 2017.

FARIAS, S. C. B. A seleção, o tratamento e a difusão da informação na perspectiva do protagonismo social: um ensaio crítico. In: GOMES, Henriette Ferreira; NOVO, Hildenise Ferreira (Org.). Informação e protagonismo social. Salvador: Edufba, 2017. p. 181-188.

FIGUEIREDO, N. M. Serviços de referência \& informação. São Paulo: Polis: Associação Paulista de Bibliotecários, 1992. 
FREIRE, P. Pedagogia do oprimido. 9. ed. Rio de Janeiro: Paz \& Terra, 1981.

GOMES, H. F. Protagonismo social e mediação da informação. Logeion: Filosofia da Informação, Rio de Janeiro, v. 5, n. 2, p.10-21, mar. 2019.

GOMES, H. F. Mediação da informação e protagonismo social: relações com a vida ativa e ação comunicativa à luz de Hannah Arendt e Jürgen Habermas. In: GOMES, H. F.; NOVO, H. F. (Org.). Informação e protagonismo social. Salvador: Edufba, 2017. p. 27-43

GOMES, H. F.; NOVO, H. F. Prefácio. In: GOMES, H. F.; NOVO, H. F. (Org.). Informação e protagonismo social. Salvador: Edufba, 2017. Prefácio, p. 7-10.

KLEBA, M. E.; WENDAUSEN, A. Empoderamento: processo de fortalecimento dos sujeitos nos espaços de participação social e democratização política. Saúde e Sociedade, São Paulo, v. 18, n. 4, p.733-743, 2009.

MOURA, M. A. Narrativas culturais, protagonismo e mundo comum. In: GOMES, H. F. ; NOVO, H. F. (Org.). Informação e protagonismo social. Salvador: Edufba, 2017. p. 93-108.

PERROTTI, E. Sobre informação e protagonismo cultural. In: GOMES, H. F.; NOVO, H. F. (Org.). Informação e protagonismo social. Salvador: Edufba, 2017. p. 11-24.

SILVA, T. F.; ROMANO, V. F. Sobre o acolhimento: discurso e prática em Unidades Básicas de Saúde do município do Rio de Janeiro. Saúde Debate, Rio de Janeiro, v. 39, n. 105, p. 363-374, abr. 2015.

VERGUEIRO, W. C. S. Ética profissional versus ética social: uma abordagem sobre os mitos da Biblioteconomia. Palavra-Chave, São Paulo, v. 8, n. 2, p. 8-11, out. 1994. 